\section{David Westgarth,}

\section{Editor,}

\section{BDJ Student}

Hello, and welcome to the latest edition of BDJ Student. I want to begin this issue with a question; how much
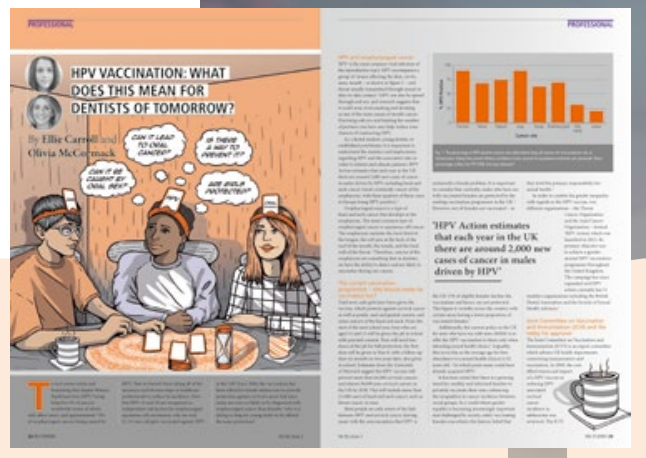

do you know about HPV? Public awareness is shockingly low - albeit on the increase - and it is a conversation that for some practitioners is not the easiest to have with patients.

Given that you're the next generation of dentists treating patients, it's useful to know what HPV is and how it

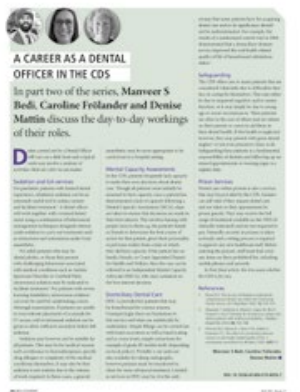
will affect discussions you have with your patients. And that's why this issue's cover feature addresses those very questions. What do students need to know about HPV? Ellie Carroll and Olivia McCormack answer that on page 22.

For some of you, your journey into dentistry is just about to begin. For some, the end is getting closer. Whichever end of the scale you find yourself at, it is never too early to think about career options. Have a read about core oral surgery, DCT, DFT and LDFT, as well as work within the Community Dental Services.

It also gives me great pleasure to

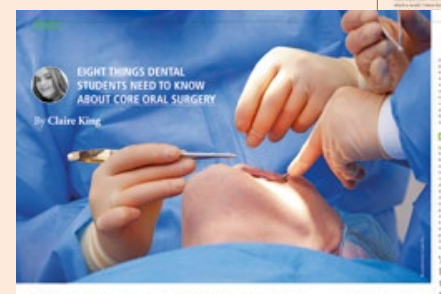
introduce our new student editor,
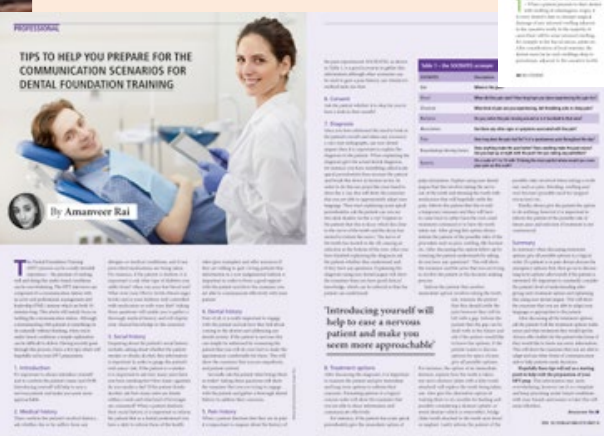

Sophie Antoniou. You can read Sophie's submission later in the issue. And finally, interviews. One question we're always being asked is 'how do I prepare?' In this issue Amanveer Rai talks you through how to prepare for FD interviews.

Enjoy the issue, and remember - you can access it online at www. nature.com/bdjstudent to exams and
Sophia Antoniou, Student editor, BDJ Student
Dear readers, I am honoured to introduce myself as the new student editor. Dentistry and literature are two huge passions of mine. The thought of being part of such an esteemed journal read by dental students all around the UK, fills me with joy. I am very much looking forward to reading articles written by peers, related to the ever-evolving field of dentistry.

September promises a fresh start to the academic year as we prepare to embark upon the new term. Some students have now reached the end of their university life and are ready to start the

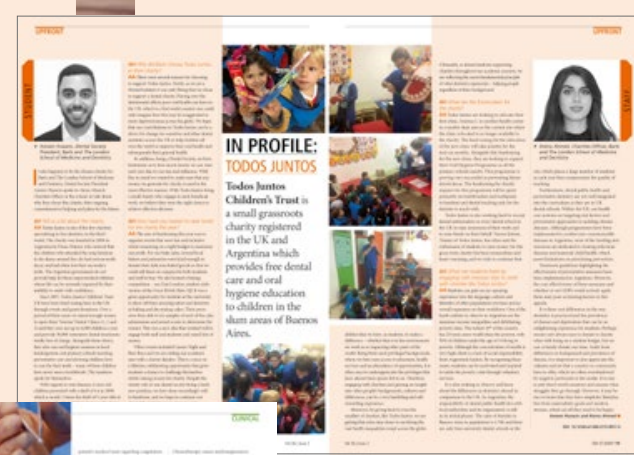
next chapter in practice, well equipped with their numerous years of training, whilst for some this is the very start of their journey.

Recently, I have been involved in several fundraisers for the charity Todos Juntos, whose aim is to enhance dental care of children in Buenos Aires, Argentina. Barts have organised their annual skydive to raise a sum of money from which these disadvantaged children can reap the benefits. Against every sensible inch of self-preservation, I have signed myself up to join the group of students that have agreed to jump out of a plane for this great cause. Skydiving has been on my bucket list for a while, so I am determined to cross it off as I set out to conquer my fears. Being afraid of heights is a hindrance which could ultimately prevent me from moving forward with positive actions. As we consider the next few terms ahead, I urge you too; to try your best to overcome any obstacles that may be withholding you from fulfilling your whole potential.

Last issue's cover feature was concerning mental health, this is a huge problem that appears to be progressively worsening. With such a demanding course it is imperative that we choose to undertake activities which will have a favourable impact on our wellbeing. These can include things like exercise, good eating habits, doing things that you have always wanted to do (even if that includes confronting your demons whether it be heights or public speaking) and talking to family and friends. The latter focus on communication is emphasised as dentistry can often be an isolating career, and we all know how beneficial good communication is in all aspects of life.

Sophia Antoniou DOI: 10.1038/s41406-019-0060-y 